\title{
Organizational Citizenship Behaviour, Hospital Corporate Image and Performance
}

\author{
- Obamiro John Kolade, Ogunnaike Olaleke Oluseye, Osibanjo Omotayo A.
}

\begin{abstract}
This study examines the relationship between organizational citizenship behaviour, hospital corporate image and performance. Questionnaires were distributed to 350 patients and 298 usable questionnaires were returned representing a return rate of $85.7 \%$. The study employs a Structural Equation Model to test four hypotheses on organizational citizenship behaviours, hospital corporate image and performance. The findings reveal that hospitals can increase performance through organizational citizenship behaviour and positive corporate image. However, it was also discovered that there is a negative covariance between organizational citizenship behaviour and hospital corporate image despite their individual positive contribution to performance. Therefore, hospital management should develop an organizational climate (such as recognition, additional reward, promotion, etc.) that can promote organizational citizenship behaviour and enhance a positive corporate image while preventing situations that will discourage staff from rendering extra positive discretionary work related services.
\end{abstract}

Keywords: organizational citizenship behaviour; hospital corporate image; healthcare; efficient service delivery; organizational performance.

JEL classification: M10

\section{INTRODUCTION}

The concept of Organizational Citizenship Behaviour (OCB) introduced by Bateman and Organ in 1983 has become a focus studied in recent years. Although the concept has been latter refined and strengthened by a number of researchers (Podsakoff, Mackenzie, Paine and Bacharach, 2000; Jahangir, 2004; Khalid and Ali, 2005; Turnipseed and Rassuli, 2005; Chi-Cheng, MengChen and Meng-Shan, 2011; Yaghoubi, Salehi and Moloudi, 2011; Sahafi, Danaee, Sarlak and Haghollahi, 2013) in different sectors of the economy. In an organizational setting, Organ and Ryan (1995) assert that organizational Citizenship Behaviour is special type of work behaviours, and is defined as individual behaviour that is beneficial to the organization and are discretionary, not directly or explicitly recognized by the formal reward system. It is often part of an informal psychological contract in which the employee hopes that such extra effort may be perceived and then rewarded by the boss and the organization (Dhitiporn and Brooklyn, 2004). Managers value OCB that creates a work environment conducive to cooperation (Buenetello et al, 2007). This makes some employees to go extra length in performing their responsibilities while others choose to withhold such appropriate work behaviours, particularly when such behaviours are not recognized, or do not result into direct or indirect benefits. Extra discretionary work behaviour has serious positive impact on work quality, actual performance, service quality and service delivery, good reputation etc., hence, corporate image. To sum it up, lack of OCB affects the organizational performance as well as image in today's highly competitive business. 
The image of a company's operations and its product (brand) is a major source of competitive advantage and is therefore a strategic asset. Kim, Kim, Kim, Kim and Kang (2008) are of the opinion that in competitive market, branding is a valuable intangible asset which it plays an important role in enabling customers to better assess and understand products, reduce customers' perceived risks in buying process. A product with clear distinctive identity is advantageous in attracting customers which later results to superior organizational performance. Although, many organizations are not conscious of passing a strong and clear message to existing and potential customers that not only differentiate their offerings from the competitors' but places in their mind unforgettable positive manner. A serious problem affecting corporate image and organizational performance is that companies are unable to properly link their identity with brand loyalty. Among ways of achieving positive corporate image is through OCB. The belief among theorists is that as more employees engage in OCB, the organization becomes more successful (Yen and Neihoff, 2004) in building corporate image and improving performance. Employees high on OCB rating will not show any Counterproductive Work Behavior (CWB) that can have negative effect on production, service delivery and promotion of corporate image. Akinbode (2005) posits that Nigerian workplace reveals that public and private organizations seem to have failed in this respect. The society has been inundated with millions of complaints from patients of both public and private health centres which invariably affect the reputation and image of the hospitals.

Nowadays, health care institutions face similar competition challenges like other service-oriented institutions like banks, telecommunication, education, insurance, etc., in areas of customer demanding for high quality services at competitive prices and delivered with courtesy and conscientiousness. Healthcare is now patient-centred, where emphases are on customer-oriented marketing (Chao-Chan, 2011). Hence, the care service market favours the buyer, rather than the seller (Lee, Chen, Chen and Chen, 2010). With the growing competition and increasingly complex business environment there is reduction in the ability to understand and anticipate the environmental requirements of organizations and as a result, organizations can not precisely formulate their staff expectations to work, because the outstanding performance is not due to the common efforts of the staff, therefore, organizations need employees with a desire to move beyond formal job expectations (Morrison, 1994 as cited in Sahafi, et al, 2013). This concept has not find proper place in medical centers (Sahafi, et al, 2013) despite the positive influence on hospital brand image. The peculiarity and sensitivity of the health care delivery has increased the requirements of OCB. Hospitals need to train and encourage their employees to discharge their duties professionally and put extra efforts $(\mathrm{OCB})$ where required.

Citizenship behaviour is most required and more important in the hospital because patients need special care and positive behaviours of medical personnel (doctors, nurses, pharmacists, etc) in handling their cases. OCB has an important role in strengthening morale and betterment of patients (Mardani-Hamole and Heydari, 2009). Also, researchers argue that citizenship behaviors facilitate access to hospital goals, and improve its performance (Chu et al, 2005). Therefore OCB will increase service efficiency, patient satisfaction and patronage, enhancing hospital corporate image as well as result to achievement of organizational performance. 
Although, several recent studies have been done on the relationship between OCB and performance (Yen and Neihoff, 2004; Buenetello et al, (2007); Chi-Cheng, et al, 2011; Yaghoubi, et al, 2011) in retail stores, other service firms but no empirical studies to our knowledge reported the linkage between $\mathrm{OCB}$, corporate image and performance in hospital. No studies directly state that medical personnel's extra efforts will affects hospital corporate image (HCI) and overall performance. Owing to organizational performance is closely related to the OCB and; corporate reputation and image may influence the performance of organization probably. Therefore, this study intends to investigate the relationship between organizational citizenship behaviors and corporate image and, how its influence performance. This article has three main objectives: to determine the existence of a direct link between OCB and hospital corporate image, to investigate the relationship between $\mathrm{OCB}$ and performance and find out how hospital corporate image can influence organization performance.

\section{LITERATURE REVIEW}

\subsection{Organizational Citizenship Behavior}

Organ (1988) opined that OCB are the various behaviours who are beneficial to the organization, but it is made spontaneously by members and never been directly or explicitly instructed in the organization formal reward system. Furthermore, OCB is not within the role or the range provided by job description, such behaviour is more similar to personal choice. In the opinion of Izhar (2009) OCB refers to "those organizationally beneficial behaviours and gestures that can neither be enforced on the basis of formal role obligations nor elicited by contractual guarantee of recompense."Since these extra ordinary efforts are optional their presence cannot be enforced (Organ, 1988), and their omission is not considered as punishable in the organizations (Van Dyne et al., 1995). Turnipseed and Rassuli (2005) mentioned the examples of these OCB behaviours as understanding and cooperation with colleagues, mentoring, performing extra duties without delay and complaint, punctuality, volunteering, efficiently use of organizational resources, sharing ideas and positively representing the organization.

Scholars differ about the characters of organizational citizenship behaviors. Smith (1983) identified altruism (behaviour targeted specifically at helping individuals) and generalized compliance (behaviour reflecting compliance with general rules, norms and expectations are the dimension of OCB. Organ (1988) developed five OCB dimensions namely altruism, courtesy, civic virtue, conscientiousness and sportsmanship. Studies later re-conceptualize OCB dimensions. Graham (1991) believes that citizenship behaviors in organizations have three categories; Organizational obedience, loyalty and participation. Piercy, Lane and Cravens (2002) included some other dimensions; cheerleading (to encourage colleagues and give hope to them) and peacemaking (dispute resolution and play agent stabilizer role). Hannam and Jimmieson, (2002) conceptualized $\mathrm{OCB}$ dimension as organization compliance and protecting organization resources and Marockzy and Xin's (2004) emphasis only sportsmanship and courtesy as OCB dimensions. In Buenetello et al's, (2007) study, the OCB dimensions examined, namely; civic duties, counter productive work behavior and time management differ from other studies. While Yaghoubi, et al (2011) grouped the OCB dimensions as non-visual (altruism, courtesy and conscientiousness) 
and virtual factors (sportsmanship and civic virtue), Chi-Cheng, et al (20011) employed four of Organ (1988) OCB dimensions (altruism, conscientiousness, sportsmanship and civic virtue) with different but similar conceptual descriptions.

In health setting, some of the OCB dimensions are essentials to provide quality and differentiate services that promote the corporate image of a hospital. Altruism is a kind of discretionary behaviour tailored towards helping and motivating other employees in discharging their duties efficiently and tackles the works related problems. This is highly required in hospitals because medical personnel must work as a team; interact with one another to achieve delivery of quality service. Conscientiousness is discretionary behaviour that helps medical staff to obey the rules of their professions, punctuality at work, attend to patient on timely and reducing waiting time. Sportsmanship is a dimension that promotes willingness to tolerate less than expected situation without complaining and finding faults. For medical staff, this spirit enables them to tolerate different patient and coworker behaviours. Courtesy indicates employee's respectful behaviours that avoid creating work-related problems with others, for example, an employee consults others before taking action to avoid creating problems for colleagues. Civic virtue is extra behaviour of responsible participation in organizational related activities with good interest and commitment. For example, doctors should coordinate their duties with hospital programmes or doing things that are not required in the duties, but can enhance the hospital corporate image.

\subsection{Hospital Corporate Image $(\mathrm{HCl})$}

In today's competitive business environment building corporate image and identity is the easier way to achieve product differentiation, attract and retain customers and attain overall organizational objectives. Image is an impression perceived by the mind of a target respondent (Berstein, 1984). Corporate image is a valuable intangible asset that describes the manner in which a company, its activities, and its products are perceived by the public. In other words, corporate image is a function of organizational communication or signals of its overall operations which determine the perceptions of customer, employees, government, competitors, suppliers, potential employees and other stakeholders. It is related to the various physical and behavioural attributes of a firm such as business name, culture, tradition, ideology, core values, products/services, and the impression of quality communicated by each person interacting with the firm's clients (Nguyen and Leblanc, 2001). Most of the attributes that promote corporate image can be put in place through employees' satisfaction and commitments toward and beyond the requirement of their duties. In some cases, the extra discretional efforts (OCB) of employees are more important in building a long lasting corporate reputation among stakeholders especially the customers, government, supplied and general public.

In the health care setting, Hospital corporate image is an impression perceived by patients about the hospital which is based on the interactions with its services, actions, activities; what they have read about the hospital and visual symbols they recognize. Chao-Chan (2011) posits that hospital brand image is not absolute; but comparable among competing hospitals. Patients view hospital corporate image from the arrival time to treatment experiences to departure. The good perception of the image of a hospital's brand is a major source of competitive advantage and it is therefore a valuable strategic asset which directly linked to hospital performance. Hospital 
corporate image are also developed by attributed of employees such as caring, nice, friendly, responsiveness, etc. A positive hospital corporate image helps in attracting and retaining patients as well as achieving overall hospital performance.

\section{INTERRELATIONSHIPS AND RESEARCH HYPOTHESES DEVELOPMENT}

\subsection{OCB and Performance}

Several past researches have established a relationship between OCB and performance in manufacturing and service organizations in developed countries but very rare in health care centres and non in Nigerian healthcare system. Most studies have been done while separating employees into two groups, the best performing and the worst performance (Buentello, Jung and Sun, 2007). Organ (1990); Werner (1994); Podsakoff, et al, (2000) Yaghoubi, et al (2011), Chao-chan, et al (2011), Baghersalimi, Reza, Keldbari, Alipour, (2011), Sahafi, et al,(2013) investigated the $\mathrm{CBO}$ related issues in different organizations and summarize that the employees extra efforts in performing their duties significantly improves organization performance in several ways: a. to improve the efficiency of colleagues and managers; b. release resources for more productive activities; c. reduce the scarce resources needed for the maintenance of the normal operation of the organization; d. assist in the coordination between work groups and groups within ; e. strengthen the ability for the organization to attract and retain talented employees; f. enhance the stability of the organization; g. make organizations more responsive to change in the environment. Bolino and Turnley, (2003) and Baghersalimi et al, (2011) investigated how OCB can also increase the organization's social capital. The attention of this study is to relate OCB to the following hospital performance variables; a. patient first choice; a patient re-visit intention; c. recommend to others; d. service efficiency. Therefore, OCB dimensions were considered as important contributors to organizational performance. That is, OCB is a great determinant of organizational success. In hospital environment therefore, it is likely that a well tailored OCB will benefit both co-workers (helping one another) and directly impact hospital performance. Thus, the first hypothesis is proposed as follow:

H1: OCB is positively related to hospital's performance

\section{2 $\mathrm{HCl}$ and Performance}

Healthcare, been an intangible product that can only be feel but not touch, the image of the hospital play a critical role in attracting and sustaining patients. There is a general belief in business operations that a favourable corporate image has a positive influence on organizational performance. Gray and Balmer (1988) posit that favourable reputation among employees can be prime causal factor of high morale and productivity. Positive corporate image makes an organization attractive to the public (both customers and employees) (Vuokko, 2002). Holtzhausen and fourie (2008) highlight that organizations benefit from being perceived positively by employees and customers. A solid corporate image can be attractive to its constituencies and they have certain perceptions about an organization before they even begin to interact (Argenti, 1998). Corporate image has been demonstrated as an important antecedent of organizational performance. 
Various organizational stakeholders have different images of the same organization but in summary corporate image cannot be evaluated based on: a. corporate communication; b. corporate identity; c. excellent facilities; d. trust in the organization perceived quality product; e. proper attitude of employees and so more. Corporate communication in this study can be described as the images a hospital projects to its stakeholders especially its patients and employees about its services. Corporate identity is referred to as the personality of the hospital in quantitative (i.e. size of the hospital, availability of modern equipment, volume of patronage) and qualitative (i.e. quality of service, reputation and image of the hospital) terms that distinguish one hospital from another and attract and retain patients. Perceived quality product means patient's judgment about the level of efficient and excellence healthcare delivery.

This study will attempt to replicate the relationship between HCI and organizational performance with focus on hospital. The overall aim of building a positive and solid HCI is to position the hospital as a first choice health centre, enhance service efficiency and patient satisfaction, build patient loyalty and re-visit intention. Therefore, a solid and positive corporate image will tend to contribute to hospital effectiveness and efficiency. Thus, we propose:

H2: HCI is positively related to performance

\subsection{OCB, $\mathrm{HCl}$ and Performance}

Literature asserted that both CB and CI contribute greatly to hospital performance. In other words, it is apparent from the preceding researches that employees' extra efforts in performing their duties beyond what are formally required of them will enhance the image of the hospital positively. Hence, Hospital citizenship behaviour appears to promote corporate image. Thus, the third hypothesis is proposed as:

H3: Citizenship Behaviour efforts have positive effects on hospital corporate image

Furthermore, "does the introduction of hospital corporate image provide a better explanation to the effect of OCB on performance?" In the health care environment, is the relationship between $\mathrm{OCB}$ and performance enhanced by a solid and positive corporate image? Hence, the fourth hypothesis is described as follow:

H4: Hospital corporate image pronounces the relationship between citizenship behaviour and performance.

In the light of above discussion, the research hypothetical model that describes the relationship between organization citizenship behavior, hospital corporate image and performance is presented in figure 1. 


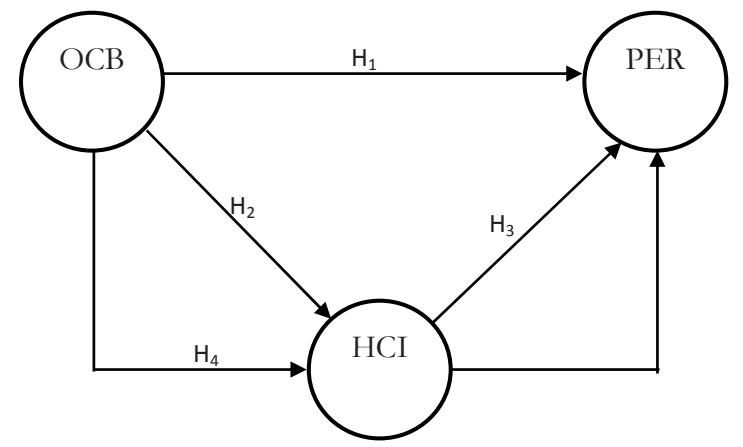

Fig. 1 - Conceptual Model of Relationship between OCB, HCI and Performance. Source: Researcher, 2013.

\section{MATERIALS AND METHODS}

This study is a survey research and data were collected through self-administered structured questionnaire from patients in three moderate-sized private hospitals in Ota, Ogun State, Nigeria. In total, 350 questionnaires were distributed. The questionnaire was categorized into three sections: Section A contains questions on patients/nurses/doctors/pharmacists demographic characteristics; section B contains questions on three constructs; organization citizenship behavior, hospital corporate image and performance. Organizational citizenship behaviour scales of Organ and Bateman (1983); Organ (1988), Buenetello et al, (2007), Yaghoubi, et al, (2011) and Baghersalimi et al, (2011) were adapted to measure OCB. The measurement of hospital corporate image used in this study was adapted from Chiou (2004), Lin and Wang (2006) and Chen and Chen, 2010) measurement of communication, corporate identity, excellent hospital facilities, proper attitude of doctors and nurse and trust in the hospital. Beside the questions on demographic characteristics, respondents answered a total of 24 questions on a 5 point Likert-scale, ranging from strongly agree to strongly agree (5= "strongly agree" and 1= "strongly disagree").

The validity of the questionnaire was confirmed by the extensive review of past studies. Cronbach's a coefficient was used to assessed the internal consistency of the questionnaire items. The reliability score was 0. 645; which was closed to the recommended acceptable level of 0.70 (Hair, Anderson, Tatham and Black, 1998). This indicates that the instrument is reliable (see Oscar, et al, 2010). This study used SPSS 17.0 and Amos 7.0 to carry out the statistical analysis. SPSS was employed to analyse the demographic data and determine the reliability of the questionnaire while Amos was used to test the study hypotheses. These hypotheses were formulated to establish the structural relationship between the organizational citizenship behaviors, hospital corporate image and performance. As shown in Figure 2, organizational citizenship behaviours have five variables, namely, altruism, conscientiousness, courtesy, sportsmanship and civic virtue; hospital corporate image has three components; corporate identity, corporate communication and perceived quality; and the four factors of the organizational performance are service efficiency, patient satisfaction, patient re-visit and recommend to others. 


\section{RESULTS AND DISCUSSION}

\section{Bio-data analysis}

Out of the 350 questionnaires distributed, 298 questionnaires were returned properly filled representing $85.7 \%$ return rate and this formed the basis of analysis in this study. Table 1 shows the respondents' social- demographic characteristics. The majority were female (66\%); male (34\%), all patients are within the age brackets of 13 to 45 ages, involving more single $(73.3 \%)$ than married patient (24.4\%). All the respondents are educated having at least SSCE/NCE/OND certificate (33\%); with 3.7\% OND/NCE holders, $49 \%$ HND/B.Sc certificate, 3.7\% M.Sc./MBA while $14.3 \%$ of the respondents are M.Sc./PhD certificates holders and uneducated were not captured in the study. Only literate patients were considered for purpose for easy understanding of the significant of the study.

Tab. 1 - Respondents' Socio-Demographic Characteristics. Source: Field Survey, 2013.

\begin{tabular}{|l|c|c|c|}
\hline Gender & Male & Female & Total \\
\hline Frequency & 101.32 & 196.68 & 298 \\
\hline Percentage & $34 \%$ & $66 \%$ & $100 \%$ \\
\hline
\end{tabular}

\begin{tabular}{|l|c|c|c|c|c|c|}
\hline Age Bracket & $13-17$ & $18-22$ & $23-27$ & $28-32$ & $33-44$ & 45 and Above \\
\hline Frequency & 26 & 156 & 39 & 25 & 24 & 28 \\
\hline Percentage & $8.7 \%$ & $52.3 \%$ & $13 \%$ & $8.3 \%$ & $8.0 \%$ & $9.7 \%$ \\
\hline
\end{tabular}

\begin{tabular}{|l|c|c|c|c|}
\hline $\begin{array}{l}\text { Educational } \\
\text { Attainment }\end{array}$ & $\begin{array}{c}\text { WACE/ } \\
\text { SSCE }\end{array}$ & $\begin{array}{c}\text { OND/ } \\
\text { NCE }\end{array}$ & $\begin{array}{c}\text { HND/ } \\
\text { B.SC. }\end{array}$ & $\begin{array}{c}\text { M.SC/ } \\
\text { PHD }\end{array}$ \\
\hline Frequency & 98 & 11 & 146 & 43 \\
\hline Percentage & $33 \%$ & $3.7 \%$ & $49 \%$ & $14.3 \%$ \\
\hline
\end{tabular}

\begin{tabular}{|l|c|c|c|}
\hline Marital Status & Single & Married & Others \\
\hline Frequency & 218.43 & 72.71 & 3.87 \\
\hline Percentage & $73.3 \%$ & $24.4 \%$ & $1.3 \%$ \\
\hline
\end{tabular}




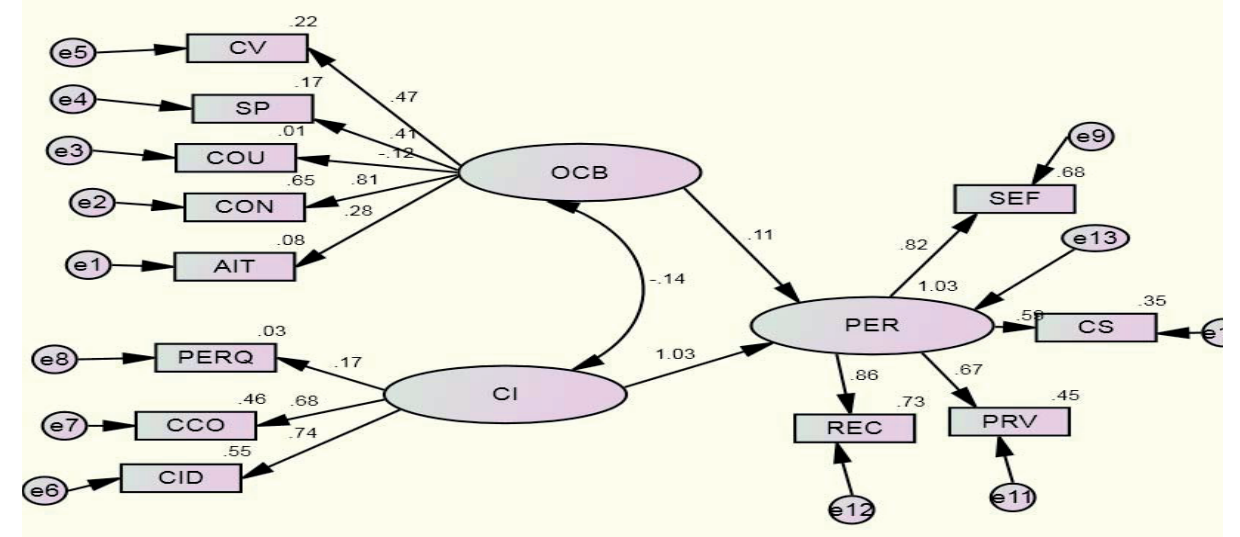

Fig. 2 - Results of structural Relationship between OCB, HCI and Performance. Source: Researcher, 2013.

\section{DISCUSSION OF RESULTS OF STRUCTURAL EQUATION MODEL}

The question items cover the factors of Organizational Citizenship Behaviour (OCB), Corporate Image (CI) and Performance (PER) as explained earlier. The factors of OCB considered in this study are; $\mathrm{CV}=$ Civic Virtue, $\mathrm{SP}=$ Sportsmanship, $\mathrm{COU}=$ Courtesy and $\mathrm{CON}=$ Altruism. The factors of $\mathrm{CI}$ are; $\mathrm{PERQ}=$ perceived Product Quality, $\mathrm{CCO}=$ Corporate Communication and $\mathrm{CID}=$ Corporate Identity. While the factors that measured PER in this study are; SEF $=$ Service Efficiency, CS = Customer Satisfaction, PRV = Patient Revisit and REC $=$ Recommend to others. The hypotheses in this study were tested using a structural model. The overall fit of the model provided an acceptable fit to the data. The comparative fit index (CFI) which one of the tests of fit of the model to the data collected has a value of .943 in this study and this is above the convention of .90 . Hence, it could be said that the model fit the data very well. Another fit index; Tucker-Lewix Index (TLI) whose value closest to 1 indicates good model fit has a value of 0.917 in this research. This indicates a great fitness of the model to the data. The normed fit index (NFI) value of 0.895 is close to recommended value of $\geq 0.09$. This exhibited a good fit with the data collected. The Incremental fit index (IFI) values close to 1 indicate a very good fit The IFI of 0.947 obtained in this study is closed the common acceptance level. Relative fit index (RFI) is another important index of model fit and the value of 0.839 obtained is close to the recommended value of 1. The Root Mean Square Error of Approximation (RMSEA) value indicates the level of error of approximation is another fit index. Values of about 0.05 or less would indicate a close fit of the model in relation to the degree of freedom and under 0.08 or less would indicate a close fit to the model and reasonable error of approximation. The finding reveals RMSEA of 0.055 , which is very close to .05, indicates a near perfect fit between the model and data. The six common model-fit indices measured were within the range of respective general acceptance levels as shown in past studies, indicating that the measurement model exhibited a good fit with the data 
collected. Therefore, we could proceed to discuss the casual relationship by examining the path coefficients of the structural model.

The results indicate the parameters of the structural path which provide the correlation and causation relationship among variables as shown in figure 2 . The result depicted that there is positive casual relationship among variables except for the covariance path between OCB and HCI that show a negative or inverse relationship. All the paths are significant related. H1 describes the casual relationship between OCB and hospital's performance. This hypothesis was supported and it means that the relationship is statistically significant. H2 which postulated a causal relationship between HCI and performance, the finding confirms that the relationship is statistically significant. This implies that hospital with a good corporate image enjoys patient patronage, hence, performance. Regarding H3 that proposed that OCB have positive effect on HCI was not supported by the path result that reveals a negative covariance relationship between the two constructs. Lastly, the negative effect between OCB and HCI contradict the fourth hypothesis that observes that HCI pronounces the relationship between citizenship behaviour and hospital's performance. This implies that OCB and HCL individually promote performance but HCL does not mediate the relationship between OCB and performance.

The findings from the hypotheses tested reveal that citizenship organization behaviours facilitate achievement of hospital performance. This implies that understanding and cooperation with colleagues, mentoring, performing extra duties without delays and complaints, punctuality, volunteering, efficiently use of organizational resources, sharing ideas and positively representing the organization will increase service efficiency, patient satisfaction, patient revisit and recommendation to others, hence, organizational performance. Our result was consistent with the findings of other previous studies (Chi-Cheng, et al 2011; Yaghoubi, et al, 2011). Also, the positive casual relationship between hospital corporate image and performance revealed by the finding implies that patients have good impression about the hospitals which is based on the interactions with their services, actions and activities. The good perception of the of hospitals services which are developed by the attributes of employees such as caring, nice, friendly, responsiveness, etc. helps in attracting and building patient loyalty and re-visit intention, thus, achieving overall hospital performance.

One may think that employees performing extra duties above and beyond what they are required without delays and complaints will have positive impact in promoting hospital image in terms of corporate communication, corporate identity excellent service delivery and trust in the organization and vice versa. But, the finding indicates a negative covariance relationship, meaning that the more employees engage in organization citizenship behaviour the less effect it has on the image of the hospital and vice versa. Therefore, the proposition that Organization citizenship behavior through hospital corporate image contributes greatly to performance did not hold but they enhance performance individually. This implies that hospital corporate image does not mediate between organizational citizenship behavior and performance. 


\section{CONCLUSION}

This study examines the structural relationship between organization citizenship behavior, hospital corporate image and performance. The findings of the three out of the four hypotheses tested in this study supported the position in the literature except the three hypotheses that showed a negative covariance relationship. This implies that an increase in organization citizenship behaviour resulted to less of hospital corporate image and vice versa. Furthermore, employees extra efforts beyond and above what are expected of them do not directly enhance corporate image but facilitate hospital performance. Hospital managers and administrators should encourage their employees to engage in more organizational citizenship behaviours to improve performance and this in turn promote good perception of the hospital services.

This study is not without its limitations. The data analysed was obtained from moderate-sized hospitals (both public and private) that vary in healthcare services provided and state of art equipment. Thus, the results of this study may not be generalized to other settings. Also, some variables of the study constructs; organization citizenship behaviour, hospital corporate image and performance were outside the scope of the study, so were not considered in this study. Furthermore, since the sample size consists of patients from these selected hospitals in the same location, the responses may not a good representative of the generality of patients in all locations. Despite limitations, the causal relationship between these constructs were carefully analysed and the findings indicates that employees performing beyond and above what are required of them per time enhances hospital performance. Patients having good perception of hospitals in terms effective and efficient service delivery improves performance. Further studies are required to be conducted in large-sized hospitals or based on large-size sample representatives in more locations. Also, the issue of the negative covariance relationship between organizational citizenship behavior and organizational corporate image should be reexamined with additional variables included in the constructs.

\section{References}

1. Akinbode, G.A. (2005). Personal factors and dispositional characteristics as predictors of job behaviour and outcomes. Lagos: Unpublished PhD Monograph.

2. Argenti, P. (1998). Corporate Communication. Boston: Irwin McGraw-Hill.

3. Baghersalimi, S., Reza, H., Keldbari, R., \& Alipour, R. H. (2011). Organizational Citizenship Behaviour and Employees social capital: A Case Study Rasht Hospitals. Australian Journal of Basic and Applied Sciences, 5(8), 1185-1193.

4. Bateman, T. S., \& Organ, D. W. (1983). Job satisfaction and the good soldier: The Relationship between affect and employee "citizenship". Academy of Management Journal, 26(4), 587-595. http://dx.doi.org/10.2307/255908

5. Bolino, M. C., \& Turnley, W. H. (2003). Going the Extra Mile: Cultivating and Managing Employee Citizenship Behaviour. Academy of Management Executive, 17(3), 60-71. http:// dx.doi.org/10.5465/AME.2003.10954754 
6. Buentello, O., Jung, J., \& Sun, J. (2007). Exploring the Casual Relationship between Organizational Citizenship Behaviour. Total Quality Management, and Performance. Unpublished Manuscript.

7. Chao-Chan, W. (2011). The Impact of Hospital Brand Image on Service Quality, Patient Satisfaction and Loyalty. African Journal of Business Management, 5(12), 4873-4882.

8. Chen, M. L., \& Chen, K. J. (2010). The Relations of Organizational Characteristics, Customer-Oriented Behaviour and Service Quality. African Journal Business Management, 4(10), 2059-2074.

9. Chi-cheng, C., Meng-Chen, T., \& Meng-Shan, T. (2011). The Organizational Citizenship Behaviours and Organizational Commitments of Organizational Members Influences the Effects of Organizational Learning. International Journal of Trade, Economics and Finance, 2(1), 61-66. http://dx.doi.org/10.7763/IJTEF.2011.V2.79

10. Chun-Chen, H., Ching-Sing, Y., \& Ming-Tien, T. (2012). A Multidimensional Analysis of Ethical Climate, Job Satisfaction, Organizational Commitment, and Organizational Citizenship Behaviours. Nursing Ethics, 19(4), 513-529. http://dx.doi.org/10.1177/096973301 1433923

11. Dhitiporn, C., \& Brooklyn, D. C. (2004). The effects of internal career orientations on organizational citizenship behavior in Thailand. Career Development International, 9(4), 406423. http://dx.doi.org/10.1108/13620430410544355

12. Graham, J. W. (1991). An Essay on Organizational Citizenship Behaviour. Employee Responsibilities and Rights Journal, 4(4), 249-270. http://dx.doi.org/10.1007/BF01385031

13. Gray, E., \& Balmer, J. (1998). Managing Corporate Image and Corporate Reputation. Long Range Planning, 3(5), 695-702. http://dx.doi.org/10.1016/S0024-6301(98)00074-0

14. Hair, J. F., Aderson, R. E., Tatham, R. L., \& Black, W. C. (1998). Multivariate Data Analysis, Upper Saddle River, NJ: Prentice-Hall Inc.

15. Hannam, R.L., \& Jimmieson, N.L. (2002). The relationship between extra-roles and job burnout for primary school Teachers: A preliminary model and development of an Organizational citizenship Behaviour scale. In: Shilton, W., Jeffrey R. Annual conference of the Australian association for research, Brisbane, 1-5(12), 1-17.

16. Holtzhausen, L., \& Fourie, L. (2008). Communicating to a Diverse Workforce: Employee's Perceptions of Symbolic Corporate Identity Element. Corporate Communication: An International Journal, 13(1), 80-94. http://dx.doi.org/10.1108/13563280810848210

17. Izhar, O. (2009). Organizational Citizenship Behaviour in Teaching: The Consequences for Teachers, Pupils, and the School. International Journal of Educational, 23, 275-389.

18. Jahangir, N. (2004). Organizational citizenship Behaviour: its nature and antecedents. BR AC University journal, 1(2), 75-85.

19. Khalid, S.A., \& Ali, H. (2005). The effect of Organizational citizenship Behaviour on withdrawal Behaviour: A Malaysian Study. International journal of management and entrepreneurship, 1(1), 30-40. 
20. Kim, K. H., Kim, K. S., Kim. D. Y., Kim J. H., \& Kang S. H. (2008). Brand Equity in Hospital Marketing. Journal of Business Research, 61(1), 75-82. http://dx.doi.org/10.1016/ j.jbusres.2006.05.010

21. Lin, H., \& Wang, Y. (2006). An Examination of the Determinants of Customer Loyalty in Mobile Commerce Contexts. Information and Management Journal, 43(3), 271-282. http:// dx.doi.org/10.1016/j.im.2005.08.001

22. Markoczy L., \& Xin, K. (2004). Antecedents and consequences of Organizational citizenship Behaviour. Journal of Service Research, 10(2).

23. Nguyen, N., \& Leblanc, G. (1998). The Mediating Role of Corporate Image on Customers' Retention Decisions: An Investigation in Financial Services. International Journal Bank Marketing, 16(2), 52-56. http://dx.doi.org/10.1108/02652329810206707

24. Organ, D.W., \& Ryan, K. (1995). A meta-analytic review of attitudinal and dispositional predicators of Organizational citizenship Behaviour. Personnel Psychology, 48(4), 775-802. http://dx.doi.org/10.1111/j.1744-6570.1995.tb01781.x

25. Organ, D. W. (1988). Organizational Citizenship Behaviour: The Good Soldier Syndrome. Lexington, MA: Lexington Books.

26. Organ, D. W. (1990). The Motivational Basis of Organizational Citizenship Behaviour, Research in Organization Behaviour. Greenwich, CT: JAI Press.

27. Podsakoff, P. M., Mackenzie, S. B., Paine, J. B., \& Bacharach, D. G. (2000). Organizational Citizenship Behaviours: A Critical Review of the Theoretical and Empirical literature and Suggestions for Future Research. Journal of Management, 26(3), 513-563.

28. Sahafi, E., Danaee, H., Sariak, A. M., \& Haghollahi, F. (2011). The Impact of Emotional Intelligence on Citizenship Behavior of Physicians with Emphasis on Infertility Specialists. Journal of Family and Reproductive. Journal of Family and Reproductive Health, 5(4), 109-115.

29. Smith, C. A., Organ, D. W., \& Near, J. P. (1983). Organizational citizenship Behaviour: Its nature and antecedents. Journal Applied Psychology, 68(4), 653-663. http://dx.doi. org/10.1037/0021-9010.68.4.653

30. Turnipseed, D. L., \& Rassuli, A.(2005). Performance Perceptions of Organizational Citizenship Behaviours at work: A bi-level Study among Managers and Employees. British Journal of Management, 16(3), 231-244. http://dx.doi.org/10.1111/j.1467-8551.2005.00456.x

31. Van Dyne, L., Graham, J., \& Dienesch, R. M. (1994). Organizational citizenship behavior: construct redefinition, measurement, and validation. Academy of Management Journal, 37(4), 762-802. http://dx.doi.org/10.2307/256600

32. Vuokko, P. (2004). Non Profit-Organization Marking. Porvoo: Werner Soderstrom Osakeyhtio (WSOY).

33. Werner, J. M. (1994). Dimensions that make a Difference: Examining the Impact of in-role and Extra-role Behaviours on Supervisory Ratings. Journal of Applied Psychology, 79(1), 98 107. http://dx.doi.org/10.1037/0021-9010.79.1.98

34. Yaghoubi, N., Salehi, M., \& Moloudi, J. (2011). Improving Service Quality by Using Organizational Citizenship Behaviour: Iranian Evidence. Iranian Journal of Management, 4(2), 79-97. 
35. Yen, H., \& Neihoff, B. (2004). Organizational citizenship Behaviour and Organizational effectiveness: Finding relation in Taiwanese banks. Journal of Applied Social Psychology, 34(8), 1617-1637. http://dx.doi.org/10.1111/j.1559-1816.2004.tb02790.x

\section{Contact information}

Obamiro John Kolade (Ph.D.)

Department of Business Administration \& Management Technology

Lagos State University, Ojo, Lagos State

Email:johnobamiro@gmail.com

Ogunnaike Olaleke Oluseye

Department of Business Management

Covenant University, Ota, Ogun State

Osibanjo Omotayo A. (Ph.D.)

Department of Business Management

Covenant University, Ota, Ogun State 